\title{
Antifibrinolytics attenuate inflammatory gene expression after cardiac surgery
}

\author{
Alexander F. L. Later, MD, ${ }^{\text {a }}$ Laura S. Sitniakowsky, MSc, ${ }^{\mathrm{b}}$ Joost A. van Hilten, PhD, \\ Leo van de Watering, PhD, ${ }^{\text {b }}$ Anneke Brand, MD, PhD, ${ }^{\text {b,c }}$ Nico P. M. Smit, PhD, ${ }^{\text {d }}$ and \\ Robert J. M. Klautz, MD, $\mathrm{PhD}^{\mathrm{a}}$
}

\begin{abstract}
Objectives: Anti-inflammatory effects of tranexamic acid and aprotinin, used to abate perioperative blood loss, are reported and might be of substantial clinical relevance. The study of messenger ribonucleic acid synthesis provides a valuable asset in evaluating the inflammatory pathways involved.
\end{abstract}

Methods: Whole-blood messenger ribonucleic acid expression of 114 inflammatory genes was compared preand postoperatively in 35 patients randomized to receive either placebo, tranexamic acid, or aprotinin. These results were further confirmed by reverse transcription-polymerase chain reaction.

Results: Of the 23 genes exhibiting independently altered postoperative gene expression levels, 8 were restricted to the aprotinin group only (growth differentiation factor 3, interleukin 19, interleukin 1 family member 7, transforming growth factor $\alpha$, tumor necrosis factor superfamily 10 , tumor necrosis factor superfamily 12 , tumor necrosis factor superfamily 13B, vascular endothelial growth factor $\alpha$ ), whereas both aprotinin and tranexamic acid altered gene expression of 3 genes as compared with placebo (FMS-related tyrosine kinase 3 ligand, growth differentiation factor 5 , interferon- $\alpha 8$ ). In general, less upregulation of pro-inflammatory, and more upregulation of anti-inflammatory, genes was observed for patients treated with antifibrinolytics. Gene expression affected by aprotinin coded mostly for proteins that function through serine proteases.

Conclusions: This study demonstrates that the use of tranexamic acid and aprotinin results in altered inflammatory pathways on the genomic expression level. We further demonstrate that the use of aprotinin leads to significant attenuation of the immune response, with several inhibitory effects restricted to the use of aprotinin only. The results aid in a better understanding of the targets of these drugs, and add to the discussion on which antifibrinolytic can best be used in the cardiac surgical patient. (J Thorac Cardiovasc Surg 2013;145:1611-6)

\section{Supplemental material is available online.}

The pharmacologic agents aprotinin and tranexamic acid have proved to reduce substantially perioperative bleeding and transfusion requirements in cardiac surgery. ${ }^{1}$ Aprotinin not only abates excess fibrinolysis, but also inhibits serine proteases involved in triggering and signaling pathways. ${ }^{2}$

\footnotetext{
From the Department of Cardiothoracic Surgery, ${ }^{\text {a }}$ Department of Haematology and Blood Transfusion, ${ }^{\mathrm{c}}$ and Department of Clinical Chemistry, ${ }^{\mathrm{d}}$ Leiden University Medical Center, Leiden, The Netherlands; and Sanquin Blood Bank Southwest, ${ }^{\text {b }}$ Leiden, The Netherlands.

This study was funded by intramural funding only; no commercial or nonprofit funding was used for this work.

Disclosures: Authors have nothing to disclose with regard to commercial support.

Clinical Trial Registration: The original trial from which the 35 subjects described herein were selected is registered at the Dutch Trial Register under no. ISRCTN00157697.

Received for publication March 6, 2012; revisions received Oct 18, 2012; accepted for publication Nov 6, 2012; available ahead of print Jan 18, 2013.

Address for reprints: Alexander F. L. Later, MD, Department of Cardiothoracic Surgery, Leiden University Medical Center, Albinusdreef 2, 2300 RC Leiden, The Netherlands (E-mail: a.f.l.later@lumc.nl).

$0022-5223 / \$ 36.00$

Copyright (c) 2013 by The American Association for Thoracic Surgery

http://dx.doi.org/10.1016/j.jtcvs.2012.11.042
}

Together with attenuation of chemotactic mediators involved in the coagulation cascade, ${ }^{3}$ this explains some of the reported anti-inflammatory effects of aprotinin. ${ }^{4-6}$ The routine use of aprotinin was questioned after results from several observational studies indicated an increased risk of serious adverse events. ${ }^{7,8}$ When aprotinin-treated, high-risk cardiac surgery patients showed a $50 \%$ increase in 30-day mortality compared with placebo or other antifibrinolytics, ${ }^{9}$ aprotinin quickly lost its dominant market position in favor of tranexamic acid. This antifibrinolytic is reported to be equally effective in reducing blood loss, ${ }^{10}$ and is thought to have similar anti-inflammatory properties as well. ${ }^{11}$ Although the impact of aprotinin and tranexamic acid on the coagulation system have been studied extensively, their effects on inflammation remain unclear. A better understanding of the signaling and regulatory pathways involved helps us to determine which positive and negative side effects are associated with their use. This is even more relevant now that the European Medicine Agency has decided that, because the results of the BART study on which this suspension was based were deemed unreliable, the current suspension of the marketing of aprotinin should be lifted. ${ }^{9,12}$ We studied pre- and postoperative messenger ribonucleic acid (mRNA) expression levels of 


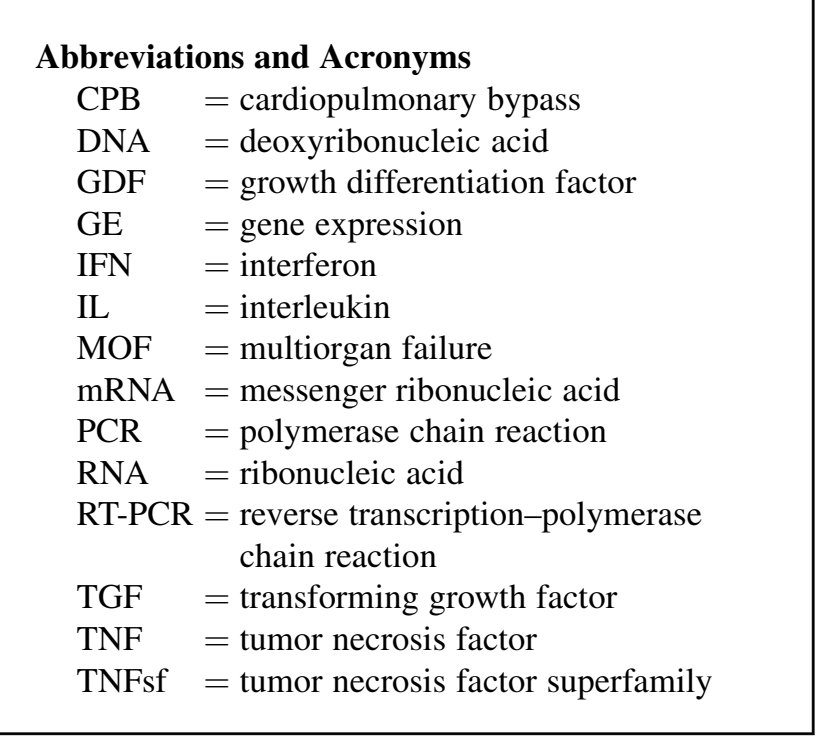

114 inflammatory genes in 35 patients randomized to receive either placebo, tranexamic acid, or aprotinin. Our primary end point was a direct comparison of aprotinin and tranexamic acid on genomic expression of genes involved in the inflammatory response, with effects on relevant clinical outcomes serving as secondary outcomes.

\section{METHODS \\ Patient Enrollment}

We performed a single-institution case-control study in which pre- and postoperative whole-blood samples were collected from 199 patients who participated in a double-blind, randomized, placebo-controlled trial evaluating the effectiveness of tranexamic acid and aprotinin between June 2004 and October 2006. ${ }^{10}$ Patients were scheduled for primary coronary bypass grafting, valvular surgery, or a combination of the 2 using cardiopulmonary bypass (CPB). Exclusion criteria encompassed active inflammatory disease and preoperative use of corticosteroids. A total of 35 patients (12 placebo, 12 tranexamic acid, 11 aprotinin), matched for age, gender, CPB time, the number of red cell blood products transfused, intraoperative use of steroids, and the incidence of postoperative multiorgan failure (MOF) were analyzed for prospective analysis of differences in pre- and postoperative inflammatory gene expression (GE) profiles. This case-control substudy was approved by our internal review board, and informed consent was obtained from each participant.

\section{Interventions}

A conventional operative approach was used in all patients, including midline sternotomy and systemic heparinization. Patients received anesthesia according to a "fast track" protocol in which total intravenous anesthesia was used through target-controlled infusion. At the time of the study, 2 of 6 cardiothoracic anesthesiologists employed at our hospital administered corticosteroids routinely to their patients, either $8 \mathrm{mg}$ dexamethasone or $80 \mathrm{mg}$ hydrocortisone. Because anesthesiologists were assigned randomly to the operations, from a patient's perspective, the administration of steroids was random. Either pulsatile or nonpulsatile blood flow was established with a centrifugal pump and hollow-fiber membrane oxygenator primed with crystalloid solution. A tip-to-tip phosphorylcholine coating of all tubing was used. Patients were randomized to receive intraoperatively either high-dose aprotinin $\left(2 \times 10^{6}\right.$ kallikrein inhibiting units aprotinin loading dose,
$2 \times 10^{6}$ kallikrein inhibiting units added to the CPB priming solution, and a continuous infusion of $5 \times 10^{5}$ kallikrein inhibiting units/hour during $\mathrm{CPB}),{ }^{13}$ full-dose tranexamic acid $(1 \mathrm{~g}$ loading dose, $500 \mathrm{mg}$ added to the CPB system prime and a continuous infusion of $400 \mathrm{mg} /$ hour during $\mathrm{CPB}),{ }^{14}$ or placebo $(0.9 \%$ saline solution according to an identical regime). Blood temperature was kept between $35^{\circ} \mathrm{C}$ and $37^{\circ} \mathrm{C}$, and myocardial protection was achieved by intermittent antegrade warm blood cardioplegia according to the Calafiore protocol. Before heparinization and after reversal with protamine, blood from the operative field was retrieved in a cell saver device, but was only washed and returned to the patient if blood loss exceeded 500 $\mathrm{mL}$. Postoperative mediastinal chest tube blood loss was not reinfused.

\section{Blood Sampling}

Whole blood samples were withdrawn by vein puncture the day before surgery and 24 hours after the start of CPB. All samples were stored immediately at $4{ }^{\circ} \mathrm{C}$ and mRNA was stabilized within 24 hours using RNALater (Applied Biosystems/Ambion, Austin, Tex). Ribonucleic acid extraction was performed with the RiboPure-blood kit (Applied Biosystems/Ambion) per the manufacturer's recommendation, including the DNase digestion step to remove residual deoxyribonucleic acid (DNA). Ribonucleic acid quantity and quality were determined using spectrophotometry, for which a 260/280 ratio $>1.8$ was deemed indicative of ribonucleic acid (RNA) of sufficient quality. In addition, we verified RNA integrity for a random selection of 5 samples with the BioAnalyzer (Agilent Technologies, Santa Clara, Calif).

\section{Arrays}

Inflammatory GE analysis was performed with a commercially available oligo GE array (OHS-021; SA Biosciences, Frederick, Md) containing 128 hybridization spots; 114 spots for cytokines and 14 spots for housekeeping genes, positive controls, and negative controls. Amplification and labeling of RNA was performed according to the TrueAMP 2.0 kit protocol (SA Biosciences). Complementary RNA was hybridized for 18 hours on the array. Chemiluminescent signal detection took place using a ChemiDoc XRS system (Bio-Rad Laboratories, Hercules, Calif), and quantification of spot intensities was conducted using the GEArray Analysis Suite (SA Biosciences). Spot intensities were corrected for the background signal by subtracting from each individual spot intensity the average value of all spot intensities per array. Gene expression values reported are fold changes $(\Delta \mathrm{GE})$, where values $<1.0$ represent a downregulation and values $>1.0$ represent upregulation of the gene.

\section{Reverse Transcription-Polymerase Chain Reaction (RT-PCR)}

Based on between-treatment group differences in $\Delta \mathrm{GE}, 8$ genes were selected for confirmation with 2-step reverse transcriptase real-time polymerase chain reaction (PCR). Assays were developed in our laboratory (Table E1). Complementary DNA was constructed using RNA applied to the arrays. Reverse transcription was performed with the SuperScript II reverse transcriptase, using random primers (Invitrogen, Carlsbad, Calif). The 7500 Fast RT-PCR (Applied Biosystems, Foster City, Calif) was used on standard modus and standard program with the GE master mix (Applied Biosystems). Each sample was run 4 times. In each run, a reference sample, consisting of pooled complementary DNA of 6 volunteer blood donors, was taken along in 4 fold. All RT-PCR output threshold cycle values were corrected for this reference sample in the same run.

\section{Clinical Evaluation and Measurements}

Preoperative baseline characteristics such as age, weight, gender, logistic EuroSCORE, use of medication, and relevant comorbidity were recorded. The preoperative laboratory investigation included a full coagulation and white blood cell profile. Intraoperatively and 24 hours postoperatively, the type of surgery, operation time, CPB time, crossclamp time, 
blood product use, and maximum white blood cell count were recorded. To evaluate the clinical impact of a changed postoperative inflammatory profile, the incidence of the systemic inflammatory response syndrome and MOF was evaluated on a daily basis during the complete period of recovery in the intensive care unit, using the systemic inflammatory response syndrome criteria proposed by the American College of Chest Physicians ${ }^{15}$ and the MOF criteria by Knaus and colleauges. ${ }^{16}$ All intra- and postoperative measurements were done by caretakers blinded to treatment group assignment.

\section{Statistical Analysis}

Clinical data were expressed as median \pm interquartile range. Demographic and perioperative clinical characteristics were compared among the 3 treatment groups using 1-way analysis of variance for continuous variables, and the $\chi^{2}$ test for categoric variables. To test for differences between pre- and postoperative GE values, Wilcoxon signed rank tests were performed. Mann-Whitney $U$ tests were performed for betweengroup comparisons. In addition, for the RT-PCR data, Mann-Whitney $U$ tests were performed to test the difference in RQr among the treatment groups. $P$ values were calculated using 2 -sided tests and were considered significant when $<.05$. The Benjamini-Hochberg correction was used to correct for the problem of multiple testing during the multiple comparison gene analysis. Statistical analysis was performed using PASW Statistics software, version 17.0.0 (SPSS, Inc, Chicago, Ill)

\section{RESULTS \\ Patients}

Patient demographics are described in Table 1. Preoperative white blood cell count, platelet count, and coagulation profiles were within the normal range for all patients (data not shown). Patients were matched with respect to age, gender, CPB time, the number of blood products transfused, intraoperative use of steroids, and the incidence of postoperative MOF. No substantial differences in terms of the type of surgery performed, the operation time, the time on CPB, and the myocardial arrest time were detected. In the postoperative patient variables, an independent lower maximum leukocyte count was seen in patients treated with either tranexamic acid $(P=.040)$ or aprotinin $(P=.018)$, with no important difference between them. No ischemic stroke or seizures were seen.

\footnotetext{
Arrays

Quantity and quality of RNA was good for all samples (data not shown). After hybridization and subtraction of the background signal, 39 of 114 genes on the array differed with respect to pre- and postoperative GE across 1 of the 3 treatment groups, with 23 genes showing significant changes between pre- and postoperative GE levels in at least 1 of the groups. Eleven of the 23 genes showed important betweengroup differences when compared with placebo: 8 genes showed differences in the aprotinin group only (growth differentiation factor [GDF] 3, interleukin [IL]-19, IL-1 family member 7, vascular endothelial growth factor $\alpha$ downregulated, transforming growth factor $[\mathrm{TGF}]-\alpha$, tumor necrosis factor superfamily [TNFsf] 10, TNFsf12, TNFsf13 upregulated), whereas 3 genes (FMS-related tyrosine kinase 3 ligand
}

downregulated, GDF-5, and interferon [IFN]- $\alpha 8$ upregulated) showed differences in both aprotinin- and tranexamic acid-treated patients. Two genes (platelet-derived growth factor $\alpha$ and TNFsf13 upregulated) showed a trend $(P<.10)$ toward independence when aprotinin-treated patients were compared with placebo (data are described in Table E2).

\section{Gene Selection for RT-PCR Confirmation}

Based on functional relevance and the amount of up- or downregulation (Table E2), 6 genes were selected for confirmation with RT-PCR: FLT3-ligand, GDF-5, IFN- $\alpha 8$, TGF$\alpha 1$, TNFsf 10 , and TNFsf 13 . We further selected 4 additional genes: CD40 ligand, TNF, IL-8, and TNFsf13b. CD40 ligand was chosen for its implication in platelet activation and reports on diminished platelet activation in aprotinintreated patients. ${ }^{17}$ Interleukin 8 had our special interest because array data indicated postoperative downregulation in all patient groups, whereas increased plasma levels have been related to patient outcome after cardiac surgery. ${ }^{18,19}$ Tumor necrosis factor and TNFsf13B were further chosen for their close functional connection to TNFsf13.

\section{Confirmation RT-PCR}

Reverse transcription-PCR assays were developed successfully for 8 selected genes. Unfortunately, GDF-5 and IFN- $\alpha 8$ GE could not be confirmed with RT-PCR because of technical difficulties during assay development. Results of the RT-PCR confirmation are presented in Table 2. Reverse transcription-PCR results were remarkably similar to GEArray results, the only difference being more pronounced upregulation in RT-PCR-confirmed upregulated genes. No independent $\Delta \mathrm{GE}$ for IL-8, TNFsf10, and TNFsf13B could be found for patients treated with aprotinin. Also, TNF GE did not change substantially in tranexamic acid-treated patients. When we tested for between-group differences (placebo vs tranexamic acid or aprotinin), TGF upregulation was less for patients treated with aprotinin ( $\triangle \mathrm{GE} \quad 1.99$ vs 5.37 , respectively; $P=.019$ ). The already noted unchanged GE of TNFsf10 in aprotinin-treated patients was confirmed and proved relevant when compared with placebo (median $\triangle \mathrm{GE}, 0.99$ vs $1.98 ; P=.042$ ). For TNFsf 13 , a trend toward independently lower upregulation in $\mathrm{GE}$ was seen in patients treated with aprotinin ( $\triangle \mathrm{GE}, 1.68$ vs $2.47 ; P=.074$ ). None of the genes tested on RT-PCR showed important differences between patients treated with tranexamic acid and placebo.

\section{Differences in Array GE Between Patients Developing MOF Versus Non-MOF Patients}

We tested further for differences in GEArray patterns of patients developing MOF $(\mathrm{n}=16)$ compared with patients not developing MOF $(n=19)$. Seventeen of the 39 genes detectable on the array showed no substantial up- or downregulation after surgery, leaving 22 genes for further 
TABLE 1. Demographic and clinical data of 35 patients

\begin{tabular}{|c|c|c|c|c|}
\hline Characteristic & $\operatorname{Placebo}(n=12)$ & Tranexamic acid $(n=12)$ & Aprotinin $(n=11)$ & $P$ value \\
\hline Age, years & $61.4(53.3-73.4)$ & $65.3(54.7-75.3)$ & $68.6(61.0-73.6)$ & .819 \\
\hline Gender, male/female, $\mathrm{n}$ & $11 / 1$ & $11 / 1$ & $8 / 3$ & .331 \\
\hline EuroSCORE, \% & $2.5(1.0-3.3)$ & $2.6(1.6-5.4)$ & $3.3(1.5-4.5)$ & \\
\hline Left ventricular ejection fraction, $\mathrm{n}$ & & & & .585 \\
\hline Moderate & 5 & 5 & 3 & \\
\hline Poor & 1 & 0 & 0 & \\
\hline Diabetes mellitus, $\mathrm{n}$ & & & & .621 \\
\hline Type 1 & 0 & 1 & 0 & \\
\hline Type 2 & 1 & 1 & 2 & \\
\hline \multicolumn{5}{|l|}{ Preoperative medication, $\mathrm{n}$} \\
\hline Acetylsalicylic acid & 7 & 6 & 5 & .820 \\
\hline Calcium antagonists & 2 & 2 & 0 & .355 \\
\hline Statins & 6 & 8 & 7 & .676 \\
\hline \multicolumn{5}{|l|}{ Operation } \\
\hline \multicolumn{5}{|l|}{ Type of surgery, $n$} \\
\hline CABG only & 5 & 5 & 3 & .716 \\
\hline Valve only & 5 & 6 & 7 & .570 \\
\hline CABG and valve & 2 & 1 & 1 & .777 \\
\hline Duration of myocardial arrest, minutes & $121(68-169)$ & $99(91-138)$ & $100(70-172)$ & .840 \\
\hline Duration of $\mathrm{CPB}$, minutes & $167(123-222)$ & $139(114-205)$ & $152(119-206)$ & .712 \\
\hline Corticosteroids, $\mathrm{n}$ & 3 & 2 & 3 & .813 \\
\hline \multicolumn{5}{|l|}{ Operation and $24 \mathrm{~h}$ postoperative } \\
\hline PRBC, units/patients transfused & $21 / 8$ & $8 / 6$ & $7 / 5$ & .586 \\
\hline FFP, units/patients transfused & $13 / 5$ & $5 / 2$ & $8 / 4$ & .460 \\
\hline Platelets, units/patients transfused & $3 / 3$ & $3 / 2$ & $2 / 2$ & .904 \\
\hline Highest leukocyte count, $\mathrm{g} / \mathrm{dL}$ & $16.1(12.8-19.6)$ & $12.5(11.0-13.1)$ & $11.1(10.3-13.1)$ & .027 \\
\hline \multicolumn{5}{|l|}{ Total ICU stay } \\
\hline Use of CVVH & 1 & 2 & 0 & .344 \\
\hline Use of IABP & 0 & 2 & 0 & .104 \\
\hline Myocardial infarction & 0 & 2 & 0 & .104 \\
\hline Incidence of SIRS, $n$ & 12 & 12 & 11 & .388 \\
\hline Incidence of MOF, $n$ & 6 & 5 & 5 & .574 \\
\hline Mortality, n & 1 & 0 & 0 & .373 \\
\hline
\end{tabular}

Data are reported as median (interquartile range). $C A B G$, Coronary artery bypass grafting; $C P B$, cardiopulmonary bypass; $P R B C$, packed red blood cell; $F F P$, fresh frozen plasma; ICU, intensive care unit; $C V V H$, continuous veno-venous hemofiltration; IABP, intra-aortal balloon pump; SIRS, systemic inflammatory response syndrome; $M O F$, multiorgan failure; EuroSCORE, European System for Cardiac Operative Risk Evaluation.

analysis. Gene expression IL-12a, IL-17b, inhibin $\alpha$, and inhibin- $\beta$ subunit A proved importantly altered after surgery, an effect not seen in the analysis of antifibrinolytic mediated GE. In contrast to non-MOF patients, MOF patients showed unchanged GE inhibin $\alpha$, inhibin- $\beta$ subunit $\mathrm{A}$, and plateletderived growth factor $\beta 24$ hours after surgery, whereas IL-12a, IL-17b, and TNFsf10 GE was changed. However, direct comparisons between MOF and non-MOF patients yielded no independent differences (data are described in Table E3).

\section{The Effect of Perioperative Corticosteroids on Array GE}

Last, we tested for the effect of intraoperative administration of corticosteroids on inflammatory GE. A total of 8 patients $(23 \%)$ received steroids intraoperatively, equally distributed across the 3 treatment groups $(P=.813)$. Of the 39 detectable genes, 20 genes had a substantially altered
GE in either corticosteroid- or noncorticosteroid-treated patients (data are described in Table E5). Again, overall differences in GE were less ( $\triangle \mathrm{GE}$ range, 0.46-1.73) than the differences observed in patients treated with either antifibrinolytic; only lymphotoxin- $\beta$ and TNFsf 13 expression differed, with stronger lymphotoxin- $\beta$ downregulation in the corticosteroid group ( $\triangle \mathrm{GE}, 0.66$ vs $0.85 ; P=.003$ ), and less TNFsf13 upregulation (1.18 vs $1.27, P=.023$ ).

\section{DISCUSSION}

The effects of aprotinin and tranexamic acid on surgical bleeding have been studied extensively, with reports indicating aprotinin to be most effective, ${ }^{20}$ whereas others conclude there is hardly any difference between them. ${ }^{21}$ More important is the issue of whether the use of antifibrinolytics is clinically advantageous. The contrary may be true; several studies reported higher incidences of complications after the use of aprotinin ${ }^{7-9}$ and tranexamic acid. ${ }^{22}$ 
TABLE 2. $\triangle$ GE RT-PCR

\begin{tabular}{lccccc}
\hline \multirow{2}{*}{ Gene } & Group & $\mathbf{n}$ & $\begin{array}{c}\boldsymbol{\Delta G E} \text {, median } \\
(\mathbf{I Q R})\end{array}$ & $\begin{array}{c}\boldsymbol{P} \text { value } \\
\text { pre- vs post }\end{array}$ & $\begin{array}{c}\boldsymbol{P} \text { value vs } \\
\text { placebo }\end{array}$ \\
\hline CD401g & PL & 12 & $0.39(0.26-0.51)$ & .002 & \\
& TX & 12 & $0.39(0.15-0.62)$ & .008 & \\
& AP & 11 & $0.24(0.11-0.37)$ & .006 & \\
FLT31g & PL & 12 & $0.26(0.15-0.37)$ & .002 & \\
& TX & 12 & $0.34(0.13-0.54)$ & .003 & .133 \\
& AP & 11 & $0.34(0.20-0.47)$ & .003 & \\
IL-8 & PL & 12 & $0.28(-0.02-0.58)$ & .019 & \\
& TX & 12 & $0.31(-0.42-0.66)$ & .012 & \\
TGF- $\alpha 1$ & AP & 11 & $0.72(0.14-1.30)$ & .182 & \\
& PL & 12 & $5.37(3.09-7.66)$ & .002 & \\
& TX & 12 & $4.05(1.33-6.78)$ & .002 & \\
TNF & AP & 11 & $1.99(0.66-3.33)$ & .008 & .019 \\
& PL & 12 & $0.71(0.51-0.92)$ & .005 & \\
& TX & 12 & $0.78(0.36-1.19)$ & & \\
TNFsf10 & AP & 11 & $0.62(0.49-0.75)$ & .010 & \\
& PL & 12 & $1.98(1.16-2.80)$ & .012 & \\
& TX & 12 & $2.10(1.35-2.85)$ & .008 & \\
& AP & 11 & $1.00(0.38-1.61)$ & & .042 \\
TNFsf13 & PL & 12 & $2.47(1.13-3.81)$ & .003 & \\
& TX & 12 & $1.99(1.06-2.92)$ & .002 & \\
TNFsf13B & AP & 11 & $1.68(1.01-2.35)$ & .075 & .074 \\
& PL & 12 & $4.98(2.51-7.44)$ & .004 & \\
& TX & 12 & $5.20(0.62-9.79)$ & .002 & \\
& AP & 11 & $3.65(1.02-6.28)$ & .004 & \\
\hline
\end{tabular}

The differences in $\triangle \mathrm{GE}$ after surgery between placebo and either tranexamic acid or aprotinin were tested with the Mann-Whitney $U$ test. Only $P$ values $<.20$ are reported here. $G E$, Gene expression; $R T-P C R$, reverse transcription-polymerase chain reaction; IQR , interquartile range; CD40lg, CD40 ligand; FLT3lg, FMS-like tyrosine kinase 3 ligand; $P L$, placebo; $T X$, tranexamic acid; $A P$, aprotinin; $I L$, interleukin; $T G F$, transforming growth factor; $T N F$, tumor necrosis factor; $T N F s f$, TNF super family member.

Anti-inflammatory properties of both aprotinin and tranexamic acid have been observed in studies evaluating plasma cytokine concentrations. ${ }^{23-26}$ Seen as messengers orchestrating the immune response, cytokines play a key role in the inflammatory response after cardiac surgery. Here we used the approach to evaluate the immune modulating properties of antifibrinolytics by studying protein synthesis at its earliest level-namely, that of transcription of the gene. This study compared the effects of tranexamic acid and aprotinin on the genomic expression level in cardiac surgery. We used an inflammatory pathway RNA gene expression array to identify unique profiles related to the use of antifibrinolytics. The results of RT-PCR confirmed the array technique, indicating that the GEArray is a suitable tool for screening for genes of interest.

We found that both antifibrinolytics alter inflammatory GE; less formation of macrophage colonies is reflected by a diminished upregulation of colony stimulating factor. Tranexamic acid and aprotinin induce a deviation toward a stronger humoral immune response through independently lower expression of IFN- $\alpha 8$, further aided by less downregulation of FMS-related tyrosine kinase 3 ligand. Common antifibrinolytic effects were also seen; aprotinin and tranexamic acid induce less upregulation of GDF-5, involved in both plasminogen activity and migration of endothelial cells. The independently lowered TGF- $\alpha 1$ expression is possibly a result of lower thrombin concentrations, and it reaches independence in the aprotinin group only, perhaps through aprotinin's additional inhibition of chemotrypsin. Last, we noticed upregulation of vascular endothelial growth factor $\alpha$ involved in synthesis of antiplasminogen activator, thus reducing fibrinolysis and clot preservation. However, most effects on GE profiles were seen in aprotinin-treated patients only with upregulation of IL-19, a cytokine with properties similar to anti-inflammatory IL-10, and IL-1 family member 7 , thereby diminishing induction of proinflammatory IFN- $\gamma$. Only aprotinin-treated patients lack upregulation of a whole range of TNFsf subclass proteins involved in apoptosis induction, B-cell proliferation, and proinflammatory cellular signaling pathways. Last, aprotinin-treated patients exhibit lower upregulation of platelet-derived growth factor $\alpha$, reflecting less platelet activation, thrombin generation, and chemotaxis of monocytes and neutrophils.

Altogether, the use of tranexamic acid and aprotinin led to less upregulation of proinflammatory genes and more upregulation of anti-inflammatory genes. Considering the GE impacted exclusively in the aprotinin group, we found these to include genes coding for proteins that function through serine proteases and genes with important antiinflammatory functioning.

Neither this study, nor the original randomized, controlled trial from which this patient group was derived, was powered to detect independent between-group differences in clinical outcomes. However, analysis of GE array profiles revealed differences between patients who developed MOF and patients who did not. Gene expression altered exclusively in MOF patients includes downregulation of IL- $12 \alpha$, a cytokine that augments the cytolytic activity of natural killer cells, and IL-17 $\beta$, depressing the release of TNF- $\alpha$ and IL- $1 \beta$ (Table E3). We further noticed downregulation of inhibin- $\beta$ A, released concurrently with TNF- $\alpha$ early in sepsis, prior to IL- $6 .{ }^{27}$ Although these differences were independent when compared with baseline values, no independent differences between MOF and non-MOF patients were seen.

Our results provide insight into the cellular mechanisms through which tranexamic acid and aprotinin exert their immune modulating effects. We identified several genetic pathways expressed differentially in patients receiving either tranexamic acid or aprotinin, with statistical independence when tested against placebo. Furthermore, several GE profiles were unique for the use of aprotinin only, with most effects induced by aprotinin's serine protease inhibition. Our study demonstrates these associations despite the small sample size, reflecting the strength of the relationship between antifibrinolytic status and particular pathway regulation. 
However, our study has limitations, too. Although patient groups were well matched according to use of corticosteroids, type of surgery, operation duration, and other relevant patient characteristics, this study lacked true randomization to the intraoperative use of corticosteroids. An additional analysis of the effects of corticosteroids on GE, however, showed only limited effects. Second, our small sample size makes it difficult to determine whether the attenuation of the inflammatory gene expression by antifibrinolytics results in clinical better recovery. Third, one can argue whether transfusions are responsible for the favorable inflammatory response seen in antifibrinolytic-treated patients. An additional analysis concentrating on GE profiles between transfused and nontransfused patient indicated small nonindependent differences (Table E4). Last, the relatively long time frame during which we studied alterations in GE might be responsible for the relatively limited number of genes with altered postoperative GE, because many plasma proteins can be measured only shortly after cardiac surgery. The fact that GE is affected 24 hours after randomization to placebo, tranexamic acid, or aprotinin, however, indicates the powerful and long-lasting effects of the use of antifibrinolytics in cardiac surgery.

\section{CONCLUSIONS}

This study demonstrates that the use of tranexamic acid and aprotinin alters inflammatory GE profiles. We further demonstrate that the use of aprotinin leads to independent attenuation of the immune response, with several inhibitory effects restricted to the use of aprotinin only, and not observed in tranexamic acid-treated patients. It is unclear from these results whether this modulated immune response plays a causal role in presumed beneficial or detrimental clinical effects after surgery. However, better understanding of the targets of these drugs enable possible adjustment of pharmacologic properties, allowing for more precise alteration of hemostasis after cardiac surgery. Our results can add further to the discussion on which antifibrinolytic, if any, can best be used in the cardiac surgical patient.

We thank M. Bogaerts for his contribution and assistance in setting up the RT-PCR confirmation of our array results.

\section{References}

1. Henry DA, Moxey AJ, Carless PA, O'Connell D, McClelland KM, Henderson KM, et al. Anti-fibrinolytic use for minimising perioperative allogeneic blood transfusion. Cochrane Database Syst Rev. 1999;4:CD001886.

2. McEvoy MD, Reeves ST, Reves JG, Spinale FG. Aprotinin in cardiac surgery: a review of conventional and novel mechanisms of action. Anesth Analg. 2007;105:949-62.

3. Levi M, Van Der Poll T. Inflammation and coagulation. Crit Care Med. 2010;38: S26-34.

4. Day JR, Taylor KM, Lidington EA, Mason JC, Haskard DO, Randi AM, et al. Aprotinin inhibits proinflammatory activation of endothelial cells by thrombin through the protease-activated receptor 1. J Thorac Cardiovasc Surg. 2006; 131:21-7.
5. Hsia TY, McQuinn TC, Mukherjee R, Deardorff RL, Squires JE, Stroud RE, et al. Effects of aprotinin or tranexamic acid on proteolytic/cytokine profiles in infants after cardiac surgery. Ann Thorac Surg. 2010;89:1843-52.

6. Graham EM, Atz AM, Gillis J, Desantis SM, Haney AL, Deardorff RL, et al. Differential effects of aprotinin and tranexamic acid on outcomes and cytokine profiles in neonates undergoing cardiac surgery. $J$ Thorac Cardiovasc Surg. 2012; 143:1069-76.

7. Karkouti K, Beattie WS, Dattilo KM, McCluskey SA, Ghannam M, Hamdy A, et al. A propensity score case-control comparison of aprotinin and tranexamic acid in high-transfusion-risk cardiac surgery. Transfusion. 2006;46:327-38.

8. Mangano DT, Miao Y, Vuylsteke A, Tudor IC, Juneja R, Filipescu D, et al. Mortality associated with aprotinin during 5 years following coronary artery bypass graft surgery. JAMA. 2007;297:471-9.

9. Fergusson DA, Hebert PC, Mazer CD, Fremes S, MacAdams C, Murkin JM, et al. A comparison of aprotinin and lysine analogues in high-risk cardiac surgery. N Engl J Med. 2008;358:2319-31.

10. Later AF, Maas JJ, Engbers FH, Versteegh MI, Bruggemans EF, Dion RA, et al. Tranexamic acid and aprotinin in low- and intermediate-risk cardiac surgery: a non-sponsored, double-blind, randomised, placebo-controlled trial. Eur J Cardiothorac Surg. 2009;36:322-9.

11. Robertshaw HJ. An anti-inflammatory role for tranexamic acid in cardiac surgery? Crit Care. 2008;12:105.

12. DeAnda A Jr, Spiess BD. Aprotinin revisited. J Thorac Cardiovasc Surg. 2012; 144:998-1002.

13. Royston D, Bidstrup BP, Taylor KM, Sapsford RN. Effect of aprotinin on need for blood transfusion after repeat open-heart surgery. Lancet. 1987;2:1289-91.

14. Dowd NP, Karski JM, Cheng DC, Carroll JA, Lin Y, James RL, et al. Pharmacokinetics of tranexamic acid during cardiopulmonary bypass. Anesthesiology. 2002;97:390-9.

15. American College of Chest Physicians/Society of Critical Care Medicine Conference. definitions for sepsis and organ failure and guidelines for the use of innovative therapies in sepsis. Chest. 1992;101:1644-55.

16. Knaus WA, Draper EA, Wagner DP, Zimmerman JE. Prognosis in acute organsystem failure. Ann Surg. 1985;202:685-93.

17. Mengistu AM, Rohm KD, Boldt J, Mayer J, Suttner SW, Piper SN. The influence of aprotinin and tranexamic acid on platelet function and postoperative blood loss in cardiac surgery. Anesth Analg. 2008;107:391-7.

18. Calafiore AM, Teodori G, Di GG, Bosco G, Mezzetti A, Lapenna D, et al. Intermittent antegrade cardioplegia: warm blood vs cold crystalloid: a clinical study. J Cardiovasc Surg (Torino). 1994;35:179-84.

19. Sablotzki A, Friedrich I, Muhling J, Dehne MG, Spillner J, Silber RE, et al. The systemic inflammatory response syndrome following cardiac surgery: different expression of proinflammatory cytokines and procalcitonin in patients with and without multiorgan dysfunctions. Perfusion. 2002;17:103-9.

20. Porte RJ, Leebeek FW. Pharmacological strategies to decrease transfusion requirements in patients undergoing surgery. Drugs. 2002;62:2193-211.

21. Casati V, Guzzon D, Oppizzi M, Bellotti F, Franco A, Gerli C, et al. Tranexamic acid compared with high-dose aprotinin in primary elective heart operations: effects on perioperative bleeding and allogeneic transfusions. J Thorac Cardiovasc Surg. 2000;120:520-7.

22. Murkin JM, Falter F, Granton J, Young B, Burt C, Chu M. High-dose tranexamic acid is associated with nonischemic clinical seizures in cardiac surgical patients. Anesth Analg. 2010;110:350-3.

23. Pruefer D, Makowski J, Dahm M, Guth S, Oelert H, Darius H, et al. Aprotinin inhibits leukocyte-endothelial cell interactions after hemorrhage and reperfusion. Ann Thorac Surg. 2003;75:210-5.

24. Greilich PE, Brouse CF, Whitten CW, Chi L, Dimaio JM, Jessen ME. Antifibrinolytic therapy during cardiopulmonary bypass reduces proinflammatory cytokine levels: a randomized, double-blind, placebo-controlled study of epsilon-aminocaproic acid and aprotinin. J Thorac Cardiovasc Surg. 2003;126: 1498-503.

25. Tassani P, Augustin N, Barankay A, Braun SL, Zaccaria F, Richter JA. High-dose aprotinin modulates the balance between proinflammatory and antiinflammatory responses during coronary artery bypass graft surgery. J Cardiothorac Vasc Anesth. 2000;14:682-6.

26. Jimenez JJ, Iribarren JL, Lorente L, Rodriguez JM, Hernandez D, Nassar I, et al. Tranexamic acid attenuates inflammatory response in cardiopulmonary bypass surgery through blockade of fibrinolysis: a case control study followed by a randomized double-blind controlled trial. Crit Care. 2007;11:R117.

27. Jones KL, de Kretser DM, Patella S, Phillips DJ. Activin A and follistatin in systemic inflammation. Mol Cell Endocrinol. 2004;225:119-25. 


\section{APPENDIX E1.}

The primer search was conducted with Primer express software (version 2.0; Applied Biosystems, Inc, Foster City, Calif). To confirm the uniqueness of the primer sequences for the gene of interest, a nucleotide blast was performed at http://www. ncbi.nlm.nih.gov/BLAST/Blast.cgi?PAGE $=$ Nucleotides $\&$
PROGRAM $=$ blastn\&MEGABLAST $=$ on\&BLAST_PROG RAMS $=$ megaBlast $\&$ PAGE_TYPE $=$ BlastSearch \&SHOW DEFAULTS $=$ on.

Genes and sequences are depicted in Table E1. All probes were labeled with fluorescein amidite dye and had nonfluorescent minor groove binder quenchers.

TABLE E1. Sequences of primers and probes for the reverse transcription-polymerase chain reaction

\begin{tabular}{|c|c|c|c|c|}
\hline $\begin{array}{c}\text { Selected } \\
\text { genes }\end{array}$ & REFSEQ ID & Forward primer & Reverse primer & Probe \\
\hline CD40lg & NM_000074 & CCA GGT GCT TCG GTG TTT GT & CCA GTG CCA TGG CTC ACT T & AAT GTG ACT GAT CCA AGC \\
\hline FLT31g & NM_001459 & TGG AGC GGC TCA AGA CTG T & TTC ACG CGC TCC AGC AA & TGG GTC CAA GAT GC \\
\hline IL-8 & NM_000584 & CAC CGG AAG GAA CCA TCT CA & AGA GCC ACG GCC AGC TT & TGT GTG TAA ACA TGA CTT C \\
\hline TGF- $\alpha$ & NM_003236 & TCC CTT GGG CCA GAT ATG TG & TCC GTT GAT TGG TCT CTA AGC A & TTG AGG CTT GAC TGT AGC AT \\
\hline TNF & NM_000594 & CTT TGG GAT CAT TGC CCT GT & GGA GGC GTT TGG GAA GGT T & AGG AGG ACG AAC ATC C \\
\hline TNFsf10 & NM_003810 & GCT CTG GGC CGC AAA AT & AGG AAT GAA TGC CCA CTC CTT & ACT CCT GGG AAT CAT \\
\hline TNFsf13 & NM_003808 & GCA GGA ACA GAG GCG TCT TC & TGG GAA TGA AAA GGG AAA AGT G & TTT GGC TCC CCG TTC C \\
\hline TNFsf13B & NM_006573 & GGC CCC AAC CTT CAA AGT TC & GCG TGA CTG CTC CCT TTC TG & AGT AGT GAT ATG GAT GAC TCC \\
\hline
\end{tabular}


TABLE E2. Fold changes in cytokine gene expression on the array for patients receiving placebo (PL), tranexamic acid (TX), and aprotinin (AP)

\begin{tabular}{|c|c|c|c|c|c|}
\hline Gene & $\begin{array}{l}\text { Medication } \\
\text { group }\end{array}$ & $\mathbf{n}$ & $\begin{array}{l}\text { RQ, median } \\
\text { (IQR) }\end{array}$ & $\begin{array}{c}P \text { value, } \\
\text { pre vs } \\
\text { post }\end{array}$ & $\begin{array}{c}P \text { value } \\
\text { vs group } 1\end{array}$ \\
\hline \multirow[t]{3}{*}{ CSF1 } & PL & 12 & $0.89(0.85-1.01)$ & .005 & \\
\hline & $\mathrm{TX}$ & 12 & $0.96(0.86-1.07)$ & NS & NS \\
\hline & AP & 11 & $1.06(0.79-1.21)$ & NS & NS \\
\hline \multirow[t]{3}{*}{ CD40lg } & PL & 12 & $0.68(0.58-0.78)$ & .004 & \\
\hline & TX & 12 & $0.77(0.58-0.90)$ & .002 & NS \\
\hline & AP & 11 & $0.71(0.57-0.84)$ & .004 & NS \\
\hline \multirow[t]{3}{*}{ FLT3lg } & PL & 12 & $0.52(0.43-0.59)$ & .002 & \\
\hline & $\mathrm{TX}$ & 12 & $0.72(0.51-0.91)$ & .003 & .033 \\
\hline & AP & 11 & $0.69(0.56-0.76)$ & .021 & .027 \\
\hline \multirow[t]{3}{*}{ GDF3 } & PL & 12 & $0.93(0.83-1.24)$ & NS & \\
\hline & $\mathrm{TX}$ & 12 & $1.02(0.79-1.19)$ & NS & NS \\
\hline & $\mathrm{AP}$ & 11 & $1.24(1.05-1.41)$ & .033 & .049 \\
\hline \multirow[t]{3}{*}{ GDF5 } & PL & 12 & $2.23(1.64-3.44)$ & .002 & \\
\hline & TX & 12 & $1.38(1.07-1.76)$ & .005 & .013 \\
\hline & $\mathrm{AP}$ & 11 & $1.11(1.06-1.48)$ & .003 & .002 \\
\hline \multirow[t]{3}{*}{ IFN- $\alpha 8$} & PL & 12 & $1.32(1.13-1.40)$ & .002 & \\
\hline & $\mathrm{TX}$ & 12 & $1.08(1.02-1.19)$ & .010 & .008 \\
\hline & AP & 11 & $0.98(0.94-1.07)$ & NS & .001 \\
\hline \multirow[t]{3}{*}{ TXLN- $\alpha$} & PL & 12 & $0.96(0.82-1.08)$ & NS & \\
\hline & TX & 12 & $1.01(0.86-1.10)$ & NS & NS \\
\hline & AP & 11 & $0.88(0.76-0.97)$ & .033 & NS \\
\hline \multirow[t]{3}{*}{ IL-19 } & PL & 12 & $0.95(0.86-1.19)$ & NS & \\
\hline & $\mathrm{TX}$ & 12 & $1.07(0.92-1.21)$ & NS & NS \\
\hline & $\mathrm{AP}$ & 11 & $1.19(1.01-1.44)$ & .026 & .049 \\
\hline \multirow[t]{3}{*}{ IL- $1 \beta$} & PL & 12 & $1.10(0.95-1.36)$ & .041 & \\
\hline & $\mathrm{TX}$ & 12 & $1.24(1.01-1.35)$ & .006 & NS \\
\hline & $\mathrm{AP}$ & 11 & $1.33(0.90-1.53)$ & .026 & NS \\
\hline \multirow[t]{3}{*}{ IL-1F7 } & PL & 12 & $0.97(0.90-1.10)$ & NS & \\
\hline & $\mathrm{TX}$ & 12 & $1.05(0.93-1.16)$ & NS & NS \\
\hline & $\mathrm{AP}$ & 11 & $1.14(1.02-1.26)$ & .033 & .027 \\
\hline \multirow[t]{3}{*}{ IL-8 } & PL & 12 & $0.50(1.80-0.91)$ & .034 & \\
\hline & $\mathrm{TX}$ & 12 & $0.43(0.23-0.61)$ & .015 & NS \\
\hline & $\mathrm{AP}$ & 11 & $0.58(0.38-0.69)$ & .041 & NS \\
\hline \multirow[t]{3}{*}{ LT $-\beta$} & PL & 12 & $0.86(0.63-1.00)$ & .012 & \\
\hline & $\mathrm{TX}$ & 12 & $0.79(0.59-1.17)$ & .028 & NS \\
\hline & $\mathrm{AP}$ & 11 & $0.83(0.64-1.15)$ & .041 & NS \\
\hline \multirow[t]{3}{*}{$\operatorname{PDGF} \alpha$} & PL & 12 & $1.23(1.13-1.33)$ & .004 & \\
\hline & $\mathrm{TX}$ & 12 & $1.12(1.06-1.24)$ & .019 & NS \\
\hline & $\mathrm{AP}$ & 11 & $1.10(1.07-1.27)$ & .013 & NS \\
\hline \multirow[t]{3}{*}{ TGF- $\alpha$} & PL & 12 & $1.60(1.51-1.85)$ & .003 & \\
\hline & $\mathrm{TX}$ & 12 & $1.43(1.17-1.60)$ & .002 & NS \\
\hline & $\mathrm{AP}$ & 11 & $1.16(0.98-1.39)$ & .016 & .014 \\
\hline \multirow[t]{3}{*}{ TNF } & PL & 12 & $0.87(0.76-0.98)$ & .015 & \\
\hline & $\mathrm{TX}$ & 12 & $0.92(0.83-1.11)$ & NS & NS \\
\hline & $\mathrm{AP}$ & 11 & $0.75(0.67-0.94)$ & .016 & NS \\
\hline \multirow[t]{3}{*}{ TNFsf10 } & PL & 12 & $1.40(1.07-1.73)$ & .041 & \\
\hline & $\mathrm{TX}$ & 12 & $1.36(1.18-1.61)$ & .010 & NS \\
\hline & AP & 11 & $0.93(0.68-1.34)$ & NS & .036 \\
\hline \multirow[t]{3}{*}{ TNFsf 12} & PL & 12 & $1.21(0.99-1.47)$ & .028 & \\
\hline & $\mathrm{TX}$ & 12 & $1.04(0.85-1.14)$ & NS & NS \\
\hline & AP & 11 & $0.92(0.77-1.03)$ & NS & .003 \\
\hline
\end{tabular}

TABLE E2. Continued

\begin{tabular}{cccccc}
\hline \multirow{6}{*}{ Gene } & $\begin{array}{c}\text { Medication } \\
\text { group }\end{array}$ & n & $\begin{array}{c}\text { RQ, median } \\
\text { (IQR) }\end{array}$ & $\begin{array}{c}\text { P value, } \\
\text { pre vs } \\
\text { post }\end{array}$ & $\begin{array}{c}\boldsymbol{P} \text { value } \\
\text { vs group 1 }\end{array}$ \\
\hline TNFsf13 & PL & 12 & $1.21(1.08-1.35)$ & .006 & \\
& TX & 12 & $1.18(1.06-1.26)$ & .015 & NS \\
& AP & 11 & $1.08(0.93-1.21)$ & NS & NS \\
TNFsf13b & PL & 12 & $1.87(1.24-4.00)$ & .002 & \\
& TX & 12 & $1.72(1.49-2.27)$ & .002 & NS \\
& AP & 11 & $1.24(0.74-1.67)$ & NS & .027 \\
TNFsf14 & PL & 12 & $1.27(1.12-1.45)$ & .005 & \\
& TX & 12 & $1.34(1.04-1.52)$ & .023 & NS \\
& AP & 11 & $1.07(1.05-1.27)$ & .021 & NS \\
TNFsf9 & PL & 12 & $0.71(0.41-1.08)$ & .034 & \\
& TX & 12 & $0.68(0.57-0.95)$ & .023 & NS \\
& AP & 11 & $0.75(0.65-0.98)$ & .016 & NS \\
VEGF $\alpha$ & PL & 12 & $0.93(0.90-0.98)$ & .019 & \\
& TX & 12 & $1.02(0.90-1.08)$ & NS & NS \\
& AP & 11 & $1.03(0.93-1.08)$ & NS & .036 \\
VEGF $\beta$ & PL & 12 & $0.87(0.72-0.93)$ & .034 & \\
& TX & 12 & $0.84(0.72-1.07)$ & .023 & NS \\
& AP & 11 & $0.70(0.67-0.88)$ & .006 & NS \\
\hline
\end{tabular}

Gene expression (GE) values on the array. Pre- and postoperative values are expressed as fold changes compared with the average expression on each array. The difference in GE values are fold changes after surgery compared with before surgery. $C S F 1$, Colony stimulating factor-1; $R Q$, relative quantitation; $I Q R$, interquartile range; $C S F$, cerebrospinal fluid; $P L$, placebo; $T X$, tranexamic acid; $A P$, aprotinin; $N S$, not significant; $C D 40 l g$, CD40 ligand; FLT3lg, FMS-like tyrosine kinase 3 ligand; $G D F$, growth differentiation factor; $I F N$, interferon; $T X L N$, taxilin; $I L$, interleukin; $L T$, lymphotoxin; $P D G F$, platelet-derived growth factor; $T G F$, transforming growth factor; $T N F$, tumor necrosis factor; TNFsf, TNF super family member; VEGF, vascular endothelial growth factor. 
TABLE E3. Fold changes in cytokine gene expression on the array for patients developing and not developing MOF

\begin{tabular}{|c|c|c|c|c|c|}
\hline Gene & MOF & $\mathbf{n}$ & $\begin{array}{c}\text { RQ, median } \\
\text { (IQR) }\end{array}$ & $\begin{array}{c}P \text { value, } \\
\text { pre vs post }\end{array}$ & $\begin{array}{c}\text { Between- } \\
\text { group } \\
P \text { value } \\
\end{array}$ \\
\hline \multirow[t]{2}{*}{ FLT31g } & No & 19 & $0.67(0.51-0.84)$ & .001 & \\
\hline & Yes & 16 & $0.55(0.49-0.69)$ & .000 & NS \\
\hline \multirow[t]{2}{*}{ GDF5 } & No & 19 & $1.38(0.11-1.85)$ & .000 & NS \\
\hline & Yes & 16 & $1.56(1.11-3.44)$ & .001 & \\
\hline \multirow[t]{2}{*}{ IFN- $\alpha 8$} & No & 19 & $1.07(1.00-1.15)$ & .003 & NS \\
\hline & Yes & 16 & $1.13(1.07-1.36)$ & .005 & \\
\hline \multirow[t]{2}{*}{ IL- $12 \alpha$} & No & 19 & $1.00(0.94-1.15)$ & NS & NS \\
\hline & Yes & 16 & $0.94(0.91-1.02)$ & .023 & \\
\hline \multirow[t]{2}{*}{ TXLN- $\alpha$} & No & 19 & $0.59(0.80-1.04)$ & .018 & NS \\
\hline & Yes & 16 & $0.99(0.88-1.08)$ & NS & \\
\hline \multirow[t]{2}{*}{ IL- $17 \beta$} & No & 19 & $0.95(0.86-1.23)$ & NS & NS \\
\hline & Yes & 16 & $0.92(0.76-1.02)$ & .049 & \\
\hline \multirow[t]{2}{*}{ IL-1 $\beta$} & No & 19 & $1.17(0.98-1.35)$ & .003 & NS \\
\hline & Yes & 16 & $1.21(0.94-1.43)$ & .011 & \\
\hline \multirow[t]{2}{*}{ IL-8 } & No & 19 & $0.50(0.24-0.64)$ & .004 & NS \\
\hline & Yes & 16 & $0.48(0.23-0.67)$ & .011 & \\
\hline \multirow[t]{2}{*}{ INH- $\alpha$} & No & 19 & $1.08(1.01-1.16)$ & .013 & NS \\
\hline & Yes & 16 & $1.06(0.97-1.17)$ & NS & \\
\hline \multirow[t]{2}{*}{ INH- $\beta \mathrm{A}$} & No & 19 & $1.04(0.99-1.16)$ & .040 & NS \\
\hline & Yes & 16 & $0.95(1.12-1.07)$ & NS & \\
\hline \multirow[t]{2}{*}{ LT- $\beta$} & No & 19 & $0.83(0.74-1.15)$ & .027 & NS \\
\hline & Yes & 16 & $0.77(0.57-0.95)$ & .001 & \\
\hline \multirow[t]{2}{*}{ PDGF- $\alpha$} & No & 19 & $1.22(1.09-1.30)$ & .001 & NS \\
\hline & Yes & 16 & $1.13(1.07-1.24)$ & .002 & \\
\hline \multirow[t]{2}{*}{ PDGF- $\beta$} & No & 19 & $1.10(0.99-1.30)$ & .013 & NS \\
\hline & Yes & 16 & $1.04(0.84-1.21)$ & NS & \\
\hline \multirow[t]{2}{*}{ TGF- $\alpha$} & No & 19 & $1.30(1.11-1.57)$ & .001 & NS \\
\hline & Yes & 16 & $1.49(1.88-1.73)$ & .001 & \\
\hline \multirow[t]{2}{*}{ TNF } & No & 19 & $0.90(0.80-1.00)$ & .016 & NS \\
\hline & Yes & 16 & $0.82(0.70-1.02)$ & .010 & \\
\hline \multirow[t]{2}{*}{ TNFsf10 } & No & 19 & $1.30(0.92-1.46)$ & NS & NS \\
\hline & Yes & 16 & $1.34(1.06-1.69)$ & .034 & \\
\hline \multirow[t]{2}{*}{ TNFsf13 } & No & 19 & $1.18(1.00-1.23)$ & .008 & NS \\
\hline & Yes & 16 & $1.14(1.07-1.26)$ & .001 & \\
\hline \multirow[t]{2}{*}{ TNFsf13B } & No & 19 & $1.49(1.07-1.76)$ & .001 & NS \\
\hline & Yes & 16 & $1.81(1.29-3.10)$ & .002 & NS \\
\hline \multirow[t]{2}{*}{ TNFsf14 } & No & 19 & $1.24(1.04-1.53)$ & .005 & \\
\hline & Yes & 16 & $1.17(1.06-1.41)$ & .001 & NS \\
\hline \multirow[t]{2}{*}{ CD40lg } & No & 19 & $0.69(0.55-0.80)$ & .000 & \\
\hline & Yes & 16 & $0.73(0.61-0.92)$ & .001 & NS \\
\hline \multirow[t]{2}{*}{ TNFsf9 } & Yes & 19 & $0.74(0.55-1.11)$ & .011 & \\
\hline & No & 16 & $0.65(0.47-0.86)$ & .000 & NS \\
\hline \multirow[t]{2}{*}{ VEGF $\beta$} & Yes & 19 & $0.83(0.70-0.91)$ & .005 & \\
\hline & No & 16 & $0.81(0.69-1.05)$ & .023 & NS \\
\hline \multicolumn{6}{|c|}{$\begin{array}{l}\text { Gene expression (GE) values on the array. Pre- and postoperative values are expressed } \\
\text { as fold changes compared with the average expression on each array. The difference } \\
\text { in GE values are fold changes after surgery compared with before surgery. } M O F, \text { Mul- } \\
\text { tiorgan failure; } R Q \text {, relative quantitation; } I Q R \text {, interquartile range; } F L T Z L G \text {, FMS- } \\
\text { like tyrosine kinase } 3 \text { ligand; } N S \text {, not significant; } G D F \text {, growth differentiation factor; } \\
I F N \text {, interferon; } I L \text {, interleukin; } T X L N \text {, taxilin; } I N H \text {, inhibin; } L T \text {, lymphotoxin; } P D G F \text {, } \\
\text { platelet-derived growth factor; } T G F \text {, transforming growth factor; } T N F \text {, tumor necrosis } \\
\text { factor; } T N F s f \text {, TNF super family member; } C D 40 l g, \text { CD } 40 \text { ligand; } V E G F \text {, vascular en- } \\
\text { dothelial growth factor. }\end{array}$} \\
\hline
\end{tabular}

TABLE E4. Fold changes in cytokine gene expression on the array for patients transfused and not transfused with either packed red blood cells, fresh frozen plasma, or thrombocytes

\begin{tabular}{|c|c|c|c|c|c|}
\hline Gene & Transfused & $\mathbf{n}$ & $\begin{array}{c}\text { RQ, median } \\
(\mathrm{IQR})\end{array}$ & $\begin{array}{c}P \text { value, } \\
\text { pre vs post }\end{array}$ & $\begin{array}{c}\text { Between- } \\
\text { group } \\
P \text { value } \\
\end{array}$ \\
\hline \multirow[t]{2}{*}{ FLT31g } & No & 14 & $0.73(0.54-0.88)$ & .001 & \\
\hline & Yes & 21 & $0.56(0.48-0.70)$ & .000 & NS \\
\hline \multirow[t]{2}{*}{ GDF3 } & No & 14 & $1.03(0.90-1.22)$ & .030 & \\
\hline & Yes & 21 & $1.03(0.79-1.33)$ & NS & NS \\
\hline \multirow[t]{2}{*}{ GDF5 } & No & 14 & $1.48(1.21-1.92)$ & .001 & \\
\hline & Yes & 21 & $1.38(1.08-2.36)$ & .000 & NS \\
\hline \multirow[t]{2}{*}{ IFN- $\alpha 8$} & No & 14 & $1.08(1.03-1.25)$ & .016 & \\
\hline & Yes & 21 & $1.13(0.98-1.32)$ & .001 & NS \\
\hline \multirow[t]{2}{*}{ IL-19 } & No & 14 & $1.07(0.96-1.20)$ & .022 & \\
\hline & Yes & 21 & $1.05(0.84-1.25)$ & NS & NS \\
\hline \multirow[t]{2}{*}{ IL-1 } & No & 14 & $1.25(1.02-1.35)$ & .030 & \\
\hline & Yes & 21 & $1.20(0.96-1.43)$ & .002 & NS \\
\hline \multirow[t]{2}{*}{ IL-1F7 } & No & 14 & $1.04(0.93-1.14)$ & .006 & \\
\hline & Yes & 21 & $1.08(0.93-1.18)$ & NS & NS \\
\hline \multirow[t]{2}{*}{ IL-8 } & No & 14 & $0.52(0.27-0.63)$ & .002 & \\
\hline & Yes & 21 & $0.42(0.21-0.85)$ & .013 & NS \\
\hline \multirow[t]{2}{*}{$\mathrm{INH}-\alpha$} & No & 14 & $1.04(0.99-1.14)$ & .008 & \\
\hline & Yes & 21 & $1.08(0.98-1.16)$ & NS & NS \\
\hline \multirow[t]{2}{*}{ LT- $\beta$} & No & 14 & $0.88(0.55-1.18)$ & .026 & \\
\hline & Yes & 21 & $0.83(0.65-0.95)$ & .002 & NS \\
\hline \multirow[t]{2}{*}{$\operatorname{PDGF} \alpha$} & No & 14 & $1.21(1.03-1.25)$ & .004 & \\
\hline & Yes & 21 & $1.22(0.10-1.32)$ & .001 & NS \\
\hline \multirow[t]{2}{*}{ PDGF $\beta$} & No & 14 & $0.99(1.57-1.26)$ & .019 & \\
\hline & Yes & 21 & $1.07(0.88-1.20)$ & NS & NS \\
\hline \multirow[t]{2}{*}{ TGF- $\alpha$} & No & 14 & $1.43(1.19-1.65)$ & .005 & \\
\hline & Yes & 21 & $1.41(1.09-1.76)$ & .000 & NS \\
\hline \multirow[t]{2}{*}{ TNF } & No & 14 & $0.88(0.79-1.11)$ & NS & \\
\hline & Yes & 21 & $0.85(0.72-0.99)$ & .003 & NS \\
\hline \multirow[t]{2}{*}{ TNFsf10 } & No & 14 & $1.32(1.03-1.43)$ & NS & \\
\hline & Yes & 21 & $1.33(0.82-1.75)$ & .005 & NS \\
\hline \multirow[t]{2}{*}{ TNFsf13 } & No & 14 & $1.14(1.05-1.28)$ & .009 & \\
\hline & Yes & 21 & $1.17(1.03-1.26)$ & .001 & NS \\
\hline \multirow[t]{2}{*}{ TNFsf $13 b$} & No & 14 & $1.69(1.47-2.00)$ & .004 & \\
\hline & Yes & 21 & $1.50(1.07-2.76)$ & .000 & NS \\
\hline \multirow[t]{2}{*}{ TNFsf14 } & No & 14 & $1.23(1.05-1.62)$ & .019 & \\
\hline & Yes & 21 & $1.11(1.04-1.44)$ & .000 & NS \\
\hline \multirow[t]{2}{*}{ CD401g } & No & 14 & $0.79(0.67-0.86)$ & .001 & \\
\hline & Yes & 21 & $0.66(0.55-0.77)$ & .000 & NS \\
\hline \multirow[t]{2}{*}{ CD70 } & No & 14 & $1.05(0.97-1.11)$ & .035 & \\
\hline & Yes & 21 & $1.03(0.91-1.13)$ & NS & NS \\
\hline \multirow[t]{2}{*}{ TNFsf9 } & No & 14 & $0.74(0.58-1.02)$ & .008 & \\
\hline & Yes & 21 & $0.70(0.46-0.96)$ & .009 & NS \\
\hline \multirow[t]{2}{*}{ VEGF $\beta$} & No & 14 & $0.84(0.70-1.04)$ & .001 & \\
\hline & Yes & 21 & $0.75(0.69-0.89)$ & .007 & NS \\
\hline
\end{tabular}

Gene expression (GE) values on the array. Pre- and postoperative values are expressed as fold changes compared with the average expression on each array. The difference in GE values are fold changes after surgery compared with before surgery. $R Q$, Relative quantitation; $I Q R$, interquartile range; $F L 3 l g$, FMS-like tyrosine kinase 3 ligand; $N S$, not significant; $G D F$, growth differentiation factor; $I F N$, interferon; $I L$, interleukin; $I N H$, inhibin; $L T$, lymphotoxin; $P D G F$, platelet-derived growth factor; $T G F$, transforming growth factor; $T N F$, tumor necrosis factor; TNFsf, TNF super family member; $C D 40 l g$, CD40 ligand; $V E G F$, vascular endothelial growth factor. 
TABLE E5. Fold changes in cytokine gene expression on the array for patients that received corticosteroids intraoperatively and those who did not

\begin{tabular}{|c|c|c|c|c|c|}
\hline Gene & Steroids & $\mathbf{n}$ & $\begin{array}{l}\text { RQ, median } \\
\text { (IQR) }\end{array}$ & $\begin{array}{l}P \text { value, } \\
\text { pre vs post }\end{array}$ & $\begin{array}{c}\text { Between- } \\
\text { group } \\
P \text { value }\end{array}$ \\
\hline \multirow[t]{2}{*}{ CSF3 } & No & 27 & $0.93(0.87-0.99)$ & .037 & \\
\hline & Yes & 8 & $1.03(1.01-1.12)$ & NS & NS \\
\hline \multirow[t]{2}{*}{ FLT31g } & No & 27 & $0.63(0.51-0.83)$ & $<.001$ & \\
\hline & Yes & 8 & $0.58(0.36-0.69)$ & .012 & NS \\
\hline \multirow[t]{2}{*}{ GDF5 } & No & 27 & $1.48(1.11-2.30)$ & $<.001$ & \\
\hline & Yes & 8 & $1.35(1.06-1.76)$ & .012 & NS \\
\hline \multirow[t]{2}{*}{ IFN- $\alpha 8$} & No & 27 & $1.13(1.03-1.33)$ & .001 & \\
\hline & Yes & 8 & $1.05(0.98-1.27)$ & .012 & NS \\
\hline \multirow[t]{2}{*}{ TXLN- $\alpha$} & No & 27 & $0.95(0.80-1.08)$ & .022 & \\
\hline & Yes & 8 & $0.91(0.75-1.03)$ & NS & NS \\
\hline \multirow[t]{2}{*}{ IL- $1 \beta$} & No & 27 & $1.28(1.03-1.36)$ & $<.003$ & \\
\hline & Yes & 8 & $1.04(0.94-1.48)$ & NS & NS \\
\hline \multirow[t]{2}{*}{ IL-8 } & No & 27 & $0.50(0.24-0.64)$ & $<.001$ & \\
\hline & Yes & 8 & $0.46(0.22-1.84)$ & NS & NS \\
\hline \multirow[t]{2}{*}{ INH- $\alpha$} & No & 27 & $1.05(0.99-1.16)$ & NS & \\
\hline & Yes & 8 & $1.12(1.04-1.23)$ & .036 & NS \\
\hline \multirow[t]{2}{*}{ INH- $\beta$} & No & 27 & $1.01(0.97-1.04)$ & NS & \\
\hline & Yes & 8 & $1.06(0.96-1.16)$ & .017 & NS \\
\hline \multirow[t]{2}{*}{ LT $-\beta$} & No & 27 & $0.85(0.71-1.15)$ & .003 & \\
\hline & Yes & 8 & $0.69(0.54-0.82)$ & .012 & .003 \\
\hline \multirow[t]{2}{*}{ PDGF- $\alpha$} & No & 27 & $1.13(1.07-1.30)$ & $<.001$ & \\
\hline & Yes & 8 & $1.20(1.11-1.24)$ & .012 & NS \\
\hline \multirow[t]{2}{*}{ TGF- $\alpha$} & No & 27 & $1.42(1.13-1.64)$ & $<.001$ & \\
\hline & Yes & 8 & $1.40(1.08-1.71)$ & .017 & NS \\
\hline \multirow[t]{2}{*}{ TNF } & No & 27 & $0.91(0.76-1.00)$ & .004 & \\
\hline & Yes & 8 & $0.79(0.72-0.85)$ & NS & NS \\
\hline \multirow[t]{2}{*}{ TNFsf10 } & No & 27 & $1.35(1.00-1.62)$ & .016 & \\
\hline & Yes & 8 & $1.04(0.74-1.32)$ & NS & NS \\
\hline \multirow[t]{2}{*}{ TNFsf13 } & No & 27 & $1.18(1.02-1.26)$ & .001 & \\
\hline & Yes & 8 & $1.27(1.06-1.30)$ & .025 & .023 \\
\hline \multirow[t]{2}{*}{ TNFsf13B } & No & 27 & $1.73(1.37-2.70)$ & $<.001$ & \\
\hline & Yes & 8 & $1.26(0.75-1.50)$ & NS & NS \\
\hline \multirow[t]{2}{*}{ TNFsf14 } & No & 27 & $1.24(1.05-1.50)$ & $<.001$ & \\
\hline & Yes & 8 & $1.12(0.94-1.30)$ & NS & NS \\
\hline \multirow[t]{2}{*}{ CD401g } & No & 27 & $0.94(0.57-0.84)$ & $<.001$ & \\
\hline & Yes & 8 & $0.64(0.57-0.74)$ & .017 & NS \\
\hline \multirow[t]{2}{*}{ TNFsf9 } & No & 27 & $0.70(0.53-0.98)$ & .001 & \\
\hline & Yes & 8 & $0.81(0.65-0.81)$ & .036 & NS \\
\hline \multirow[t]{2}{*}{ VEGF- $\beta$} & No & 27 & $0.85(0.68-1.00)$ & .001 & \\
\hline & Yes & 8 & $0.71(0.70-0.82)$ & .017 & NS \\
\hline \multicolumn{6}{|c|}{$\begin{array}{l}R Q \text {, Relative quantitation; } I Q R \text {, interquartile range; } C S F \text {, cerebrospinal fluid; } N S \text {, not } \\
\text { significant; } F L 3 l g, \text { FMS-like tyrosine kinase } 3 \text { ligand; } G D F \text {, growth differentiation } \\
\text { factor; } I F N \text {, interferon; } T X L N \text {, taxillin; } I L \text {, interleukin; } I N H \text {, inhibin; } L T \text {, lympho- } \\
\text { toxin; } P D G F \text {, platelet-derived growth factor; } T G F, \text { transforming growth factor; } \\
T N F \text {, tumor necrosis factor; } T N F s f \text {, TNF super family member; } C D 40 l g, C D 40 \\
\text { ligand; } V E G F \text {, vascular endothelial growth factor } \alpha \text {. }\end{array}$} \\
\hline
\end{tabular}

